\title{
Ethanol Enhances Reactivated Fear Memories
}

\author{
Hiroshi Nomura*,' and Norio Matsuki' \\ 'Laboratory of Chemical Pharmacology, Graduate School of Pharmaceutical Sciences, The University of Tokyo, Tokyo, Japan
}

\begin{abstract}
Although ethanol has been shown to impair acquisition of memory, its effect on consolidated memories is not clear. Recent reports revealed that memory retrieval converted consolidated memory into a labile state and initiated the reconsolidation process. In the present study, we have demonstrated the effect of ethanol on reactivated fear memory. We used contextual fear conditioning where rats were conditioned with mild footshock, re-exposed to the training context for $2 \mathrm{~min}$, immediately injected with ethanol or saline, and finally tested $48 \mathrm{~h}$ after re-exposure. Ethanol-treated groups demonstrated longer freezing and the effect lasted for 2 weeks. Reactivation is necessary for this effect. Injection of ethanol itself did not induce a fearful response. Reactivated and ethanol-treated rats exhibited longer freezing than non-reactivated controls, suggesting that ethanol does not inhibit the memory decline but facilitates the fear memory. Two minute re-exposures induced no or little extinction. The effect of ethanol was specific for 2-min reactivation, which induces reconsolidation. Moreover, we found that picrotoxin inhibited the memory enhancement that was produced by ethanol administered just after the reactivation. These studies demonstrate that ethanol enhances reactivated contextual fear memories via activation of $\mathrm{GABA}_{\mathrm{A}}$ receptors.
\end{abstract}

Neuropsychopharmacology (2008) 33, 2912-2921; doi: 10. 1038/npp.2008. I3; published online 20 February 2008

Keywords: ethanol; fear conditioning; consolidation; reconsolidation; retrieval; GABA

\section{INTRODUCTION}

A number of studies have reported the effects that ethanol has on acquiring new memories. In human and animal studies, when ethanol is administrated prior to training, there are impairments in memory acquisition (Lister et al, 1987). There also are several reports, which showed that ethanol has effects when administered during post-training. In humans, ethanol administered after training actually facilitates learning ability for many tasks (Parker et al, 1980; Lamberty et al, 1990; Tyson and Schirmuly, 1994; Bruce and Pihl, 1997; Hewitt et al, 1996). However, conflicting results are reported in animal studies. Administration of ethanol at post-training either enhances (Alkana and Parker, 1979; Melia et al, 1986; Prediger and Takahashi, 2003) or impairs (Aversano et al, 2002) learning. By contrast, little is known about the effect of ethanol on consolidated memories.

It was previously thought that fresh memories require time to stabilize and that once consolidated, they are insensitive to interference from physical or chemical agents. However, recent reports revealed that memory retrieval is the dynamic process that changes consolidated memory into a labile state (Nader et al, 2000; Nader, 2003;

*Correspondence: H Nomura, Laboratory of Chemical Pharmacology, Graduate School of Pharmaceutical Sciences, The University of Tokyo, 7-3-I Hongo, Bunkyo-ku, Tokyo II3-0033, Japan, Tel: +8I 3 584I 478I, Fax: +8I 358414786 ,

E-mail: hiro.nomu@f-h.nir.jp

Received 20 October 2007; revised 19 January 2008; accepted 20 January 2008
Przybyslawski and Sara, 1997). These findings suggested that old, reactivated memories undergo another round of consolidation, a process referred to as reconsolidation. It is logical to hypothesize that ethanol ingestion in conjunction with memory retrieval influences memory reconsolidation and alters previously consolidated memory.

To test this hypothesis, we exposed rats to contextual fear conditioning. Our objective was to isolate the effects of ethanol on several memory processes by using different schedules of administration (Abel and Lattal, 2001).

\section{MATERIALS AND METHODS}

\section{Animals}

All experiments were conducted according to the Guide for Care and Use of Laboratory Animals, Japan Neuroscience Society. Male Sprague-Dawley rats (8-9 weeks olds, weighing 235-329 g; SLC, Shizuoka, Japan) were used in this study. Two or three rats were housed in a cage and maintained on a 12-h light/dark cycle. Food and water were provided ad libitum. Behavioral tasks were performed during the dark phase of the cycle.

\section{Contextual Fear Conditioning}

The day before the start of conditioning, the rats were brought to the experimental room and placed individually in chamber $\mathrm{A}$ for $5 \mathrm{~min}$ and then returned to their home cages. Chamber A had an acrylic flat floor and some toys for 
the rats. The conditioning session consisted of placing the rats in chamber $\mathrm{B}$ and delivering a footshock $180 \mathrm{~s}$ later. Chamber B had a metal grid floor, which was connected with a shock scrambler (SGS-003DX; Muromachi KIKAI, Tokyo, Japan). Both chambers A and B were identical in size (30 (length) $\times 25$ (width) $\times 30 \mathrm{~cm}$ (height) $)$. Rats were returned to their home cage $90 \mathrm{~s}$ after the footshock. For the reactivation session, rats were re-exposed to chamber $\mathrm{B}$ for varying lengths of time (2 or $30 \mathrm{~min}$ ) and were not exposed to the footshock. For contextual testing, rats were re-exposed to chamber $\mathrm{B}$ for $10 \mathrm{~min}$. Fear memory was assessed as the percentage of time rats spent freezing (defined as complete lack of movement, except for respiration) in chamber $B$. The reactivation session and contextual testing were video recorded to score for freezing, which was automatically measured according to Miyakawa et al (2001). Images were captured at two frames per second. For each pair of successive frames, the amount of area (pixels) within which the rat moved was measured. When this area was below a certain threshold (ie, 170 pixels) for more than $1 \mathrm{~s}$, behavior was judged as 'freezing.' When the amount of area equaled or exceeded the threshold, behavior was considered to be 'nonfreezing.' The optimal threshold (amount of pixels) by which we judged freezing was determined by adjusting it to the amount of freezing measured by human observation.

\section{Experiment 1}

On day 1, rats were conditioned with one of three different strengths of footshock $(0.6 \mathrm{~mA}, 1 \mathrm{~s} ; 0.6 \mathrm{~mA}, 2 \mathrm{~s} ; 1 \mathrm{~mA}, 2 \mathrm{~s})$. On day 2, after they were exposed to conditioning chamber for $2 \mathrm{~min}$ for memory reactivation, they received either ethanol or saline injections. On day 4 , rats were returned to the conditioning chamber for context test.

\section{Experiment 2}

On day 1 , rats were conditioned with a footshock $(0.6 \mathrm{~mA}$, $1 \mathrm{~s})$. On day 2 , the cage groups received either ethanol or saline treatment in home cage. The reactivation groups received either ethanol or saline injections after being exposed to conditioning chamber for $2 \mathrm{~min}$ for memory reactivation. On day 4 , rats were returned to the conditioning chamber for context test.

\section{Experiment 3}

On day 1 , rats were conditioned with a footshock $(0.6 \mathrm{~mA}$, $1 \mathrm{~s})$. On day 2 , after being exposed to conditioning chamber for $30 \mathrm{~min}$ for memory extinction, they received either ethanol or saline injections. On day 4 , rats were returned to the conditioning chamber for context test.

\section{Experiment 4}

On day 1 , rats were placed into the conditioning chamber for 2 min but were not conditioned with a footshock. They received either ethanol or saline injections. On day 3, rats were returned to the conditioning chamber for context test.

\section{Experiment 5}

On day 1 , rats were conditioned with a footshock $(0.6 \mathrm{~mA}$, $1 \mathrm{~s})$. On day 2 , after being exposed to conditioning chamber for $2 \mathrm{~min}$ for memory reactivation, they received either ethanol or saline injections. Two days, 2 weeks, and 4 weeks later, rats were returned to the conditioning chamber for context test.

\section{Experiment 6}

On day 1 , rats were conditioned with a footshock $(0.6 \mathrm{~mA}$, $1 \mathrm{~s})$. On day 2 , they received ethanol ( $0.5 \mu \mathrm{g}$ per side), ethanol ( $5 \mu \mathrm{g}$ per side), or phosphate-buffered saline (PBS) microinjections into bilateral amygdala after they were exposed to conditioning chamber for $2 \mathrm{~min}$ for memory reactivation. On day 4 , rats were returned to conditioning chamber for context test.

\section{Experiment 7}

On day 1, rats were conditioned with a footshock $(0.6 \mathrm{~mA}$, $1 \mathrm{~s})$. On day 2, the cage groups received either anisomycin or PBS treatment into bilateral ventricles in home cage. The reactivation groups received either anisomycin or PBS microinjections into bilateral ventricles after they were exposed to conditioning chamber for $2 \mathrm{~min}$ for memory reactivation. On day 4 , rats were returned to conditioning chamber for context test.

\section{Experiment 8}

On day 1 , rats were conditioned with a footshock $(0.6 \mathrm{~mA}$, $1 \mathrm{~s})$. On day 2 , they received either picrotoxin or saline treatment in home cage. Twenty minutes later, they were returned to the conditioning chamber for $2 \mathrm{~min}$ for reactivation and then injected with ethanol or saline. On day 4 , rats were returned to the conditioning chamber for context test.

\section{Experiment 9}

On day 1 , the naïve group was exposed to the conditioning chamber but did not receive a footshock. The conditioned group was conditioned with a footshock $(0.6 \mathrm{~mA}, 1 \mathrm{~s})$. On day 2 , they received either picrotoxin or saline treatment in home cage. Twenty minutes later, they were returned to the conditioning chamber for $10 \mathrm{~min}$ for context test.

\section{Experiment 10}

On day 1, rats were conditioned with one of two different strengths of footshock $(0.6 \mathrm{~mA}, 1 \mathrm{~s} ; 1 \mathrm{~mA}, 2 \mathrm{~s})$ and then they received either ethanol or saline injections. On day 3 , rats were returned to the conditioning chamber for $10 \mathrm{~min}$ for context test.

\section{Surgery}

In intra-amygdalar injection experiments, we used rats that had been bilaterally implanted with 22-gauge stainless steel cannulae into amygdala under sodium pentobarbital anesthesia $(50 \mathrm{mg} / \mathrm{kg})$. Coordinates were $3 \mathrm{~mm}$ posterior 
to the bregma, $5.2 \mathrm{~mm}$ lateral to the midline, and $6.4 \mathrm{~mm}$ ventral to the brain surface. In anisomycin experiments, we used rats that had been bilaterally implanted with 22-gauge stainless steel cannulae into the cerebral ventricles under sodium pentobarbital anesthesia $(50 \mathrm{mg} / \mathrm{kg})$. Coordinates were $0.8 \mathrm{~mm}$ posterior to the bregma, $1.4 \mathrm{~mm}$ lateral to the midline, and $3 \mathrm{~mm}$ ventral to the brain surface. Rats were given at least 1 week to recover from the surgery before experimental procedures.

\section{Drugs}

Ethanol ( $1.5 \mathrm{~g} / \mathrm{kg}$, i.p.; Wako) was diluted in saline for systemic injections. At this dose, ethanol inhibits acquisition process in contextual fear conditioning (Melia et al, 1996). For intra-amygdalar injections, ethanol was diluted in PBS (PBS (-): $\mathrm{Ca}^{2+}, \mathrm{Mg}^{2+}$-free PBS: $\mathrm{NaCl}, 137 \mathrm{mM} ; \mathrm{KCl}$, $2.68 \mathrm{mM} ; \mathrm{KH}_{2} \mathrm{PO}_{4}, 1.47 \mathrm{mM} ; \mathrm{Na}_{2} \mathrm{HPO}_{4}, 8.10 \mathrm{mM}$ ). It was infused at a rate of $0.25 \mu \mathrm{l} / \mathrm{min}$. A total volume of $0.5 \mu \mathrm{l}$ of ethanol solution ( 0.1 or $1 \%$ ) or an equivalent amount of PBS was infused into each amygdala. We adopted these doses of ethanol referring to some reports (Hanchar et al, 2005; Nie et al, 2004). The infusion cannulae were left in place for 2 min to allow the solution to diffuse away from the cannula tip. Anisomycin (Sigma) was dissolved in equimolar $\mathrm{HCl}$ and diluted with PBS. The $\mathrm{pH}$ was adjusted to approximately 7 with $\mathrm{NaOH}$. It was infused at a rate of $2 \mu \mathrm{l} / \mathrm{min}$. A total volume of $2.5 \mu \mathrm{l}$ of anisomycin solution $(125 \mu \mathrm{g} / \mu \mathrm{l})$ or an equivalent amount of PBS was infused into each ventricle. The infusion cannulae were left in place for an additional minute to allow the solution to diffuse away from the cannula tip. Picrotoxin $(3.0 \mathrm{mg} / \mathrm{kg}$, i.p.; Wako) was dissolved with saline.

\section{Data Analysis}

All data are demonstrated as means \pm SEM. One-way analysis of variance (ANOVA), two-way ANOVA, repeated-measure ANOVA, or paired $t$-test were used for data analysis and post hoc comparisons were made using Student's $t$-test for differences between two groups or Fisher's Protected Least Significant Difference for differences among more than two groups.

\section{RESULTS}

\section{Effects of Post-Reactivation Injection with Ethanol}

We examined the effect of ethanol on reactivated memories. Rats were trained with one of three different strengths of footshock and re-exposed to the training context $24 \mathrm{~h}$ later, then immediately injected with ethanol $(1.5 \mathrm{~g} / \mathrm{kg})$ or saline and finally tested $48 \mathrm{~h}$ after re-exposure (Figure 1a). In case of a weaker footshock $(0.6 \mathrm{~mA}, 1 \mathrm{~s})$, a repeated-measure ANOVA comparing drug treatment (ethanol $v s$ saline) and session (reactivation $v s$ test) revealed significant interaction $(\mathrm{F}(1,44)=8.45 ; p<0.01)$ (Figure $1 \mathrm{~b})$. Post hoc analysis revealed that in reactivation session, two groups exhibited comparable freezing scores $(p>0.05)$; however, in the context test, ethanol-treated rats demonstrated significantly longer freezing than saline-treated rats $(p<0.01)$ (Figure $1 \mathrm{~b})$. With a slightly stronger conditioning $(0.6 \mathrm{~mA}$,

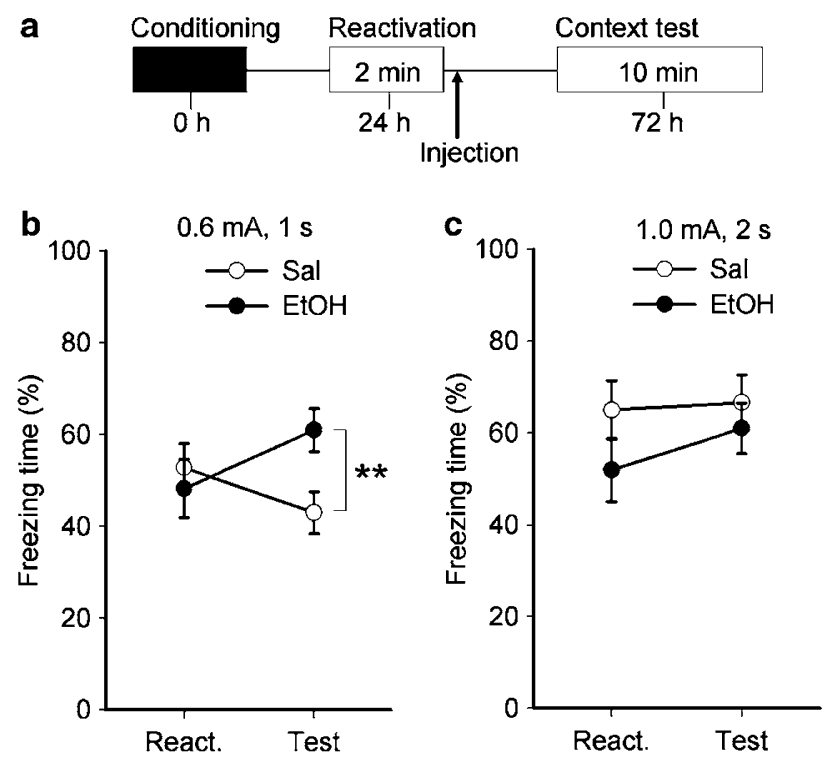

Figure I Memory enhancement by ethanol administration following 2min reactivation. (a) The behavioral procedure used for experiment I. Rats were conditioned with footshock (b, $0.6 \mathrm{~mA}$, I s; Sal (saline), $n=24$; EtOH (ethanol), $n=22 ; c, \quad$ I $m A, 2 s ;$ Sal, $n=9 ; \mathrm{EtOH}, n=9)$. (b, c) Rats conditioned with a weak footshock but not a strong footshock were sensitive to ethanol; ** $p<0.01$.

$2 \mathrm{~s}$ ), a repeated-measure ANOVA comparing the drug treatment and session also revealed a significant interaction $(\mathrm{F}(1,10)=7.42 ; p<0.05)$ (data not shown). Post hoc analysis revealed that in the reactivation session, two groups exhibited comparable freezing scores $(p>0.05)$; however, in context test, ethanol-treated rats demonstrated significantly longer freezing than saline-treated rats $(p<0.05)$. However, when footshock increased to $1 \mathrm{~mA}$ and $2 \mathrm{~s}$, an ANOVA demonstrated no significant interaction between the drug treatment and sessions $(\mathrm{F}(1,16)=0.77 ; p>0.05)$, nor was there a main effect of group $(F(1,16)=1.46$; $p>0.05$ ) (Figure 1c). Much stronger conditioned rats (two footshocks $(2.0 \mathrm{~mA}, 2 \mathrm{~s})$ ) demonstrated longer freezing $(88.0 \pm 2.9 \% ; n=6)$ compared with the rats that received a weaker conditioning $(1 \mathrm{~mA}, 2 \mathrm{~s})$ and ethanol treatment following reactivation $(\mathrm{F}(1,13)=13.9 ; p<0.01)$; it appeared that the 1-mA 2-s footshock did not reach the saturation level of freezing response (see Discussion). We tried several doses of ethanol $(0.5,1,1.5 \mathrm{~g} / \mathrm{kg})$ or saline in weak fear conditioning (footshock; $0.6 \mathrm{~mA}, 1 \mathrm{~s}$ ). The freezing levels demonstrated as percent of saline group were $110.7 \pm 25.4$ $(0.5 \mathrm{~g} / \mathrm{kg}), 140.8 \pm 24.1(1 \mathrm{~g} / \mathrm{kg})$, or $168.9 \pm 25.5 \%(1.5 \mathrm{~g} / \mathrm{kg})$, indicating a dose-dependent effect of ethanol. In the following experiments, except for cases described elsewhere, we employed weak conditioning (footshock; $0.6 \mathrm{~mA}, 1 \mathrm{~s}$ ) and $1.5 \mathrm{~g} / \mathrm{kg}$ ethanol.

We tested whether the effect of ethanol was specific for the reactivation process. Rats were divided into four groups. Two groups were re-exposed to the conditioning chamber and given saline or ethanol $24 \mathrm{~h}$ after conditioning (Figure 2a). The other two groups were given saline or ethanol without reactivation. Two-way ANOVA comparing drug treatment (ethanol $v s$ saline) and reactivation (reactivation $v s$ no reactivation) revealed significant interaction 

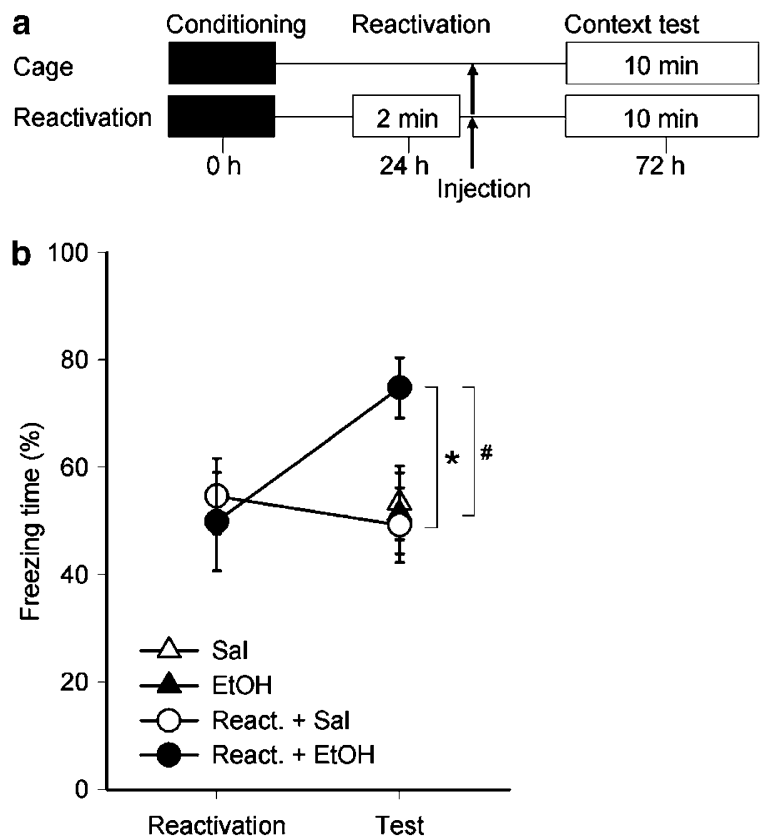

Figure 2 Effect of ethanol requires active retrieval of the memory and ethanol facilitates the fear memory rather than inhibits the decline of memory. (a) The behavioral procedure used for experiment 2. (b) While freezing in the React. $+\mathrm{EtOH}$ group was longer than that in the React. + Sal group (this result is consistent with Figure Ib), freezing in the Sal group was comparable with that in the $\mathrm{EtOH}$ group. Moreover, freezing time of the React. + EtOH group was longer than that of the $\mathrm{EtOH}$ group (Sal, $n=1$ I; $\mathrm{EtOH}, n=12$; React + Sal, $n=13$; React $+\mathrm{EtOH}, n=1$ I); ${ }^{*} p<0.05$ React. $+\mathrm{EtOH}$ vs React + Sal; ${ }^{*} p<0.05$ React. $+\mathrm{EtOH}$ vs EtOH.

$(\mathrm{F}(1,43)=4.27 ; p<0.05)$ (Figure $2 \mathrm{~b})$. Post hoc analysis revealed that the ethanol-treated rats with reactivation displayed longer freezing levels than the saline-treated rats with reactivation $(p<0.05)$; however, the two groups without reactivation were not statistically significant $(p>0.05)$. The results suggest that in order for the ethanol to have an effect, memory has to be actively retrieved.

Moreover, we tested whether extinction memory were involved to this ethanol's effect. In some cases, memory retrieval triggers extinction memory in which the conditioned stimulus comes to predict no unconditioned stimulus (US) (Rescorla and Heth, 1975). It is possible that ethanol inhibits extinction memory and ethanol-treated rats exhibit longer freezing than saline-treated rats. At first, we tested whether 2-min re-exposure induces extinction or not. The rats, which were injected with saline after reactivation, demonstrated slightly shorter freezing during context test than reactivation (Figures $1 \mathrm{~b}$ and $2 \mathrm{~b}$ ). With these data, however, we cannot determine whether the re-exposure induces extinction or not. In the strict sense, we cannot compare freezing time during reactivation with one during test, because we observed rats' behavior for 2 min during reactivation, whereas we observed the behavior for $10 \mathrm{~min}$ during test. To test the existence of extinction stringently, we compared the rats, which were injected with saline after reactivation, with the rats, which were injected with saline without reactivation. As stated above, two-way ANOVA comparing the drug treatment and reactivation revealed a significant interaction (Figure 2b). Post hoc analysis revealed that two saline-treated groups exhibited compar- able freezing (Figure 2b, Sal $v s$ React. + Sal) $(p>0.05)$, suggesting that 2 -min re-exposure induces no or little extinction. Moreover, the rats injected with ethanol after reactivation (Figure 2b, React. + EtOH group) showed longer freezing than the rats injected with ethanol without reactivation (Figure $2 \mathrm{~b}$, EtOH group) $(p<0.05)$. This suggests that ethanol facilitated the fear memory rather than inhibited the decline of memory (eg, extinction).

It is also possible that ethanol enhances spontaneous recovery from extinguished freezing level. During reactivation session, rats' freezing levels showed an upward tendency (freezing time (\%): $44.2 \pm 7.6(0-1 \mathrm{~min}), 65.1 \pm$ $8.4 \%$ (1-2 $\mathrm{min})$ ), suggesting that $2 \mathrm{~min}$ re-exposure does not induce extinction within reactivation session and does not induce spontaneous recovery.

Moreover, we applied longer reactivation paradigm. Recent studies showed that reconsolidation and extinction depend on the duration of reactivation and that reconsolidation can be triggered by short-term reactivation (Suzuki et al, 2004). To investigate whether the effect of ethanol is specific for short-term reactivation, rats were exposed to a longer reactivation session (Figure 3a). Rats were re-exposed to the conditioning chamber for $30 \mathrm{~min}$ instead of $2 \mathrm{~min}$. We measured the freezing time during the $30-\mathrm{min}$ reactivation. Freezing was relatively high in the beginning and then declined to lower levels by $10 \mathrm{~min}$. Control rats exhibited significantly less freezing responses during the last $5 \mathrm{~min}$ compared with the first $5 \mathrm{~min}$ within the 30 -min reactivation $(\mathrm{t}(1,24)=2.59 ; p<0.05)$, this probably indicated the extinction time course. Freezing time remained at low levels when tested 2 days after the reactivation. Freezing time in the test session was significantly shorter than that in the first $10 \mathrm{~min}$ of the reactivation session $(\mathrm{t}(1,24)=3.65$; $p<0.01$ ). To examine the effect of ethanol, rats were immediately administered ethanol after the 30-min reactivation. A repeated-measure ANOVA demonstrated no significant interaction between drug treatment and sessions $(\mathrm{F}(1,24)=2.82 ; p>0.05)$ (Figure $3 \mathrm{~b})$, nor was there a main effect of group $(F(1,24)=0.002 ; p>0.05)$. These data suggested that ethanol has an effect only when memory is reactivated for short term.

In previous experiments (Figures 1 and 2), we administered ethanol immediately after removing the rats from the chamber. It is possible that the injection of ethanol itself triggered fear and that the rats learned that the chamber was an aversive environment. To examine this possibility, rats were exposed to the chamber for $2 \mathrm{~min}$ without the footshock and administered ethanol or saline immediately after the exposure (Figure 3c). Two days later, we measured freezing time in the same chamber. There were no significant differences between the two groups, suggesting that the injection of ethanol itself did not induce a fearful response $(\mathrm{F}(1,10)=0.30 ; p>0.05)$ (Figure $3 \mathrm{~d}$ ).

To investigate whether the memory facilitation by ethanol during post-reactivation is maintained over the long term, contextual fear memory was assessed 2 days, 2 weeks, and 4 weeks after the injection (Figure 3e). At 2 days and 2 weeks, ethanol-treated groups demonstrated significantly longer freezing behavior $(\mathrm{F}(1,24)=6.40 ; p<0.05, \mathrm{~F}(1,24)=7.08$; $p<0.05$ ) (Figure 3f). However at 4 weeks, analysis revealed no difference between the two groups $(F(1,24)=0.39$; $p>0.05$ ). 


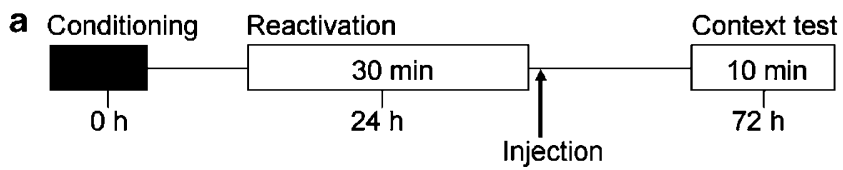

b

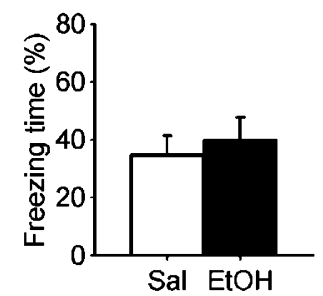

c

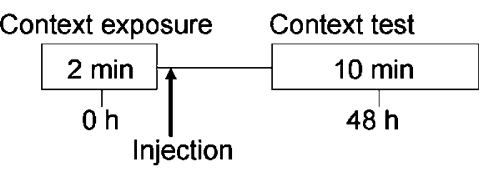

d

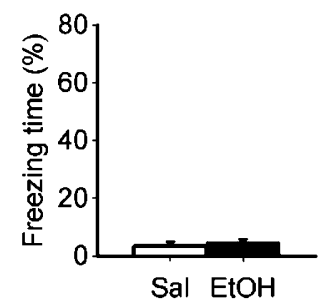

e

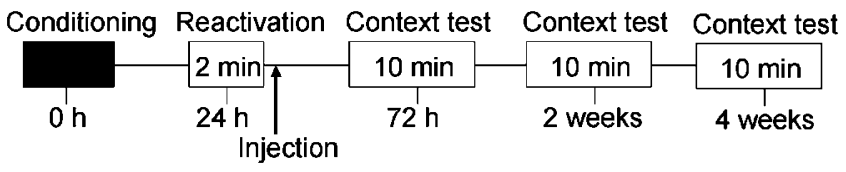

f

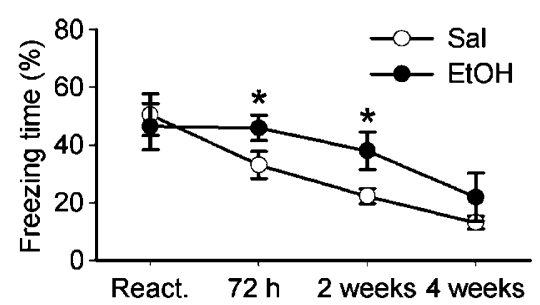

Figure 3 Ethanol following longer reactivation or context exposure did not induce memory enhancement. The effect of ethanol lasted for 2 weeks. (a) The behavioral procedure used for experiment 3 (Sal, $n=13$; EtOH, $n=13$ ). (b) There was no difference between the two groups. (c) The behavioral procedure used for experiment 4 (Sal, $n=6$; $\mathrm{EtOH}, n=6$ ). Rats were not conditioned with footshock. (d) The injection of ethanol itself did not induce a fearful response. (e) The behavioral procedure used for experiment 5 (Sal, $n=13 ; \mathrm{EtOH}, n=13)$. (f) The ethanol effect was observed at 72-h and 2-week points. Data represent freezing time for context test; $* 0<0.05$ vs saline.

One of the loci of fear memory is amygdala (LeDoux, 2000). To examine whether the memory facilitation by ethanol depends on amygdala, we tried intra-amygdalar infusions of ethanol. Rats were re-exposed to the conditioning chamber for $2 \mathrm{~min}$ and immediately afterwards bilaterally infused with ethanol or PBS into the amygdala through the implanted cannulae (Figure 4a). A repeatedmeasure ANOVA comparing drug treatment (PBS, ethanol $0.5 \mu \mathrm{g} v s$ ethanol $5 \mu \mathrm{g}$ ) and session (reactivation $v s$ test) revealed no significant interaction between the drug treatment and sessions $(F(2,17)=0.44 ; p>0.05)$, nor was
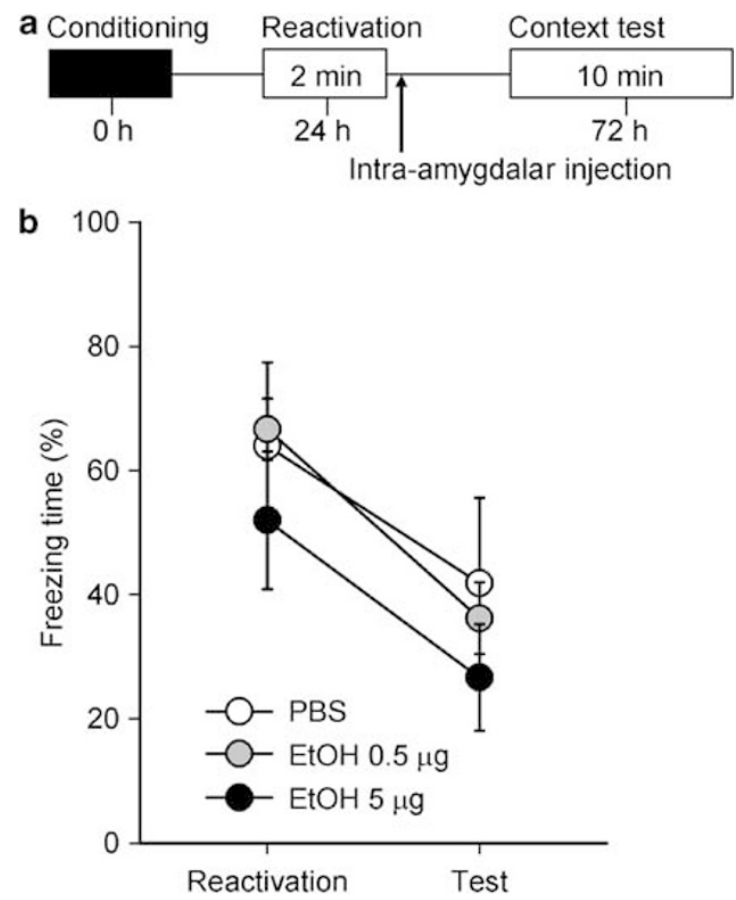

Figure 4 Intra-amygdalar microinjections of ethanol had no effect on reactivated fear memory. (a) The behavioral procedure used for experiment 6 (PBS, $n=6$; $\mathrm{EtOH} 0.5 \mu \mathrm{g}, n=8$; $\mathrm{EtOH} 5 \mu \mathrm{g}, n=6$ ). (b) Microinjections of ethanol into the amygdala following reactivation did not affect freezing behavior in the context test.

there a main effect of group $(\mathrm{F}(2,17)=0.66 ; p>0.05)$ (Figure $4 \mathrm{~b}$ ). This result suggests that the intra-amygdalar infusion of ethanol does not affect reactivated fear memories and other brain regions or some metabolic product of ethanol may be involved in the memory facilitation by ethanol.

\section{Anisomycin Disrupted Memory Reconsolidation}

Considering that ethanol has an effect only when memory is reactivated for short term, it is possible that ethanol affects memory reconsolidation. To confirm this idea, we examined whether 2-min reactivation induces reconsolidation or not. Rats were re-exposed to the conditioning chamber for $2 \mathrm{~min}$ and immediately afterwards bilaterally infused with anisomycin or PBS into the ventricles through the implanted cannulae (Figure 5a). A repeated-measure ANOVA comparing drug treatment (anisomycin vs PBS) and session (reactivation $v s$ test) revealed significant interaction $(\mathrm{F}(1,18)=9.47 ; p<0.01) \quad$ (Figure 5b). Post hoc analysis revealed that in the reactivation session, two groups exhibited comparable freezing scores $(p>0.05)$; however, in the context test, anisomycin-treated rats demonstrated significantly shorter freezing than PBS-treated rats $(p<0.05)$. Rats infused with anisomycin without reactivation were not affected $(F(1,14)=0.74 ; p>0.05)$ (Figure $5 b$ ). Memory reconsolidation is shown to depend on protein synthesis (Nader et al, 2000). Taken together, these data suggest that the 2-min reactivation process in our experiment initiated reconsolidation, whereas anisomycin blocked it. 

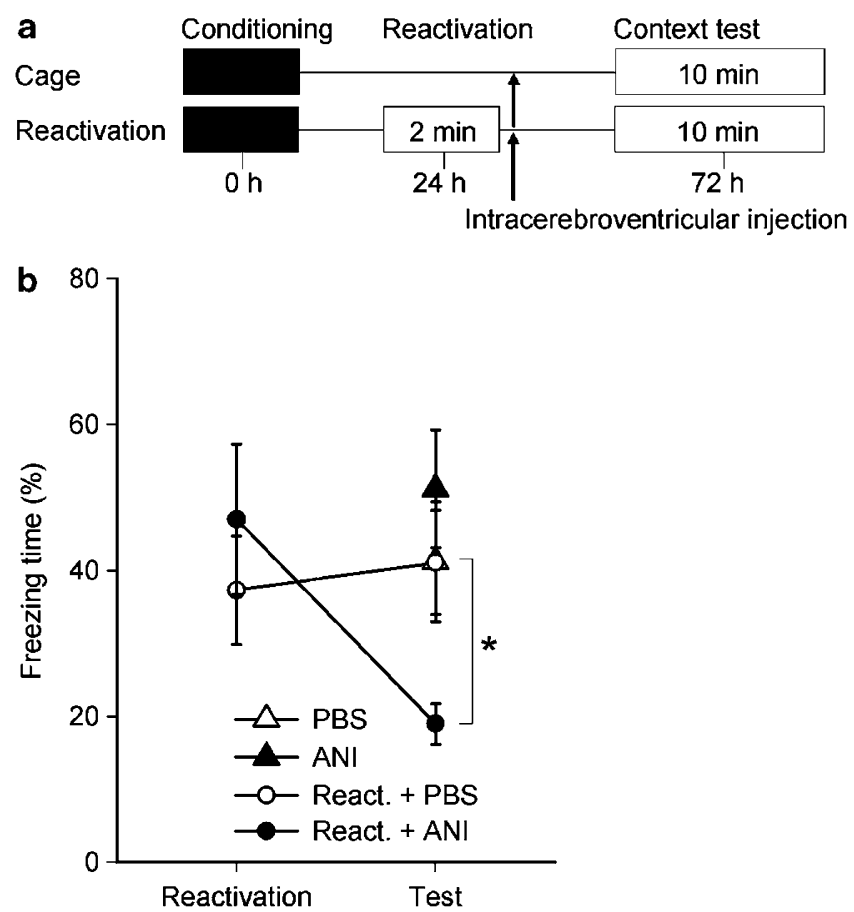

Figure 5 Intracerebroventricular microinjection of anisomycin impaired memory reconsolidation in our experiments. (a) The behavioral procedure used for experiment 7 (PBS, $n=9$; ANI (anisomycin), $n=8$; React. + PBS, $n=11$; React. $+A N I, n=9$ ). (b) Microinjection of anisomycin into ventricles following 2-min reactivation impaired long-term fear memory. Anisomycin infusion, without reactivation, had no effect; ${ }^{*} p<0.05$ React. + ANI vs React. + PBS.

\section{Picrotoxin Inhibited Memory Enhancement Induced by} Ethanol

What mechanisms are involved with memory facilitation induced by ethanol? Acute ethanol administration potentiates GABA-mediated inhibition both in vitro and in vivo, and many of the behavioral effects of ethanol are purported to be due, at least in part, to interactions with $\mathrm{GABA}_{\mathrm{A}}$ receptors (Grant and Lovinger, 1995; Crews et al, 1996). To test whether $\mathrm{GABA}_{\mathrm{A}}$ receptor-mediated mechanisms are involved in the ethanol-induced memory facilitation, we examined the effect of picrotoxin, a $G_{A B A}$ receptor antagonist, on memory facilitation by ethanol. Rats were injected with picrotoxin or saline $24 \mathrm{~h}$ after conditioning, and then 20 min later returned to the conditioning chamber for $2 \mathrm{~min}$ and then injected with ethanol or saline. Picrotoxin-treated rats demonstrated longer freezing levels at reactivation than saline-treated rats (Figure 6b), probably due to the decrease of spontaneous movements. In the contextual test, $48 \mathrm{~h}$ after reactivation, two-way ANOVA comparing pre-reactivation treatment (picrotoxin $v s$ saline) and post-reactivation treatment (ethanol $v s$ saline) revealed significant interaction $(\mathrm{F}(1,44)=5.95 ; p<0.05)$ (Figure 6b). Post hoc analysis revealed that picrotoxin treatment blocked memory enhancement induced by ethanol $(p<0.05)$. However, it is not clear whether picrotoxin-treated rats were able to recall fear memory during the reactivation session. To answer this question, additional rats were divided into two groups. The first group was conditioned with a footshock and the second group was exposed only to
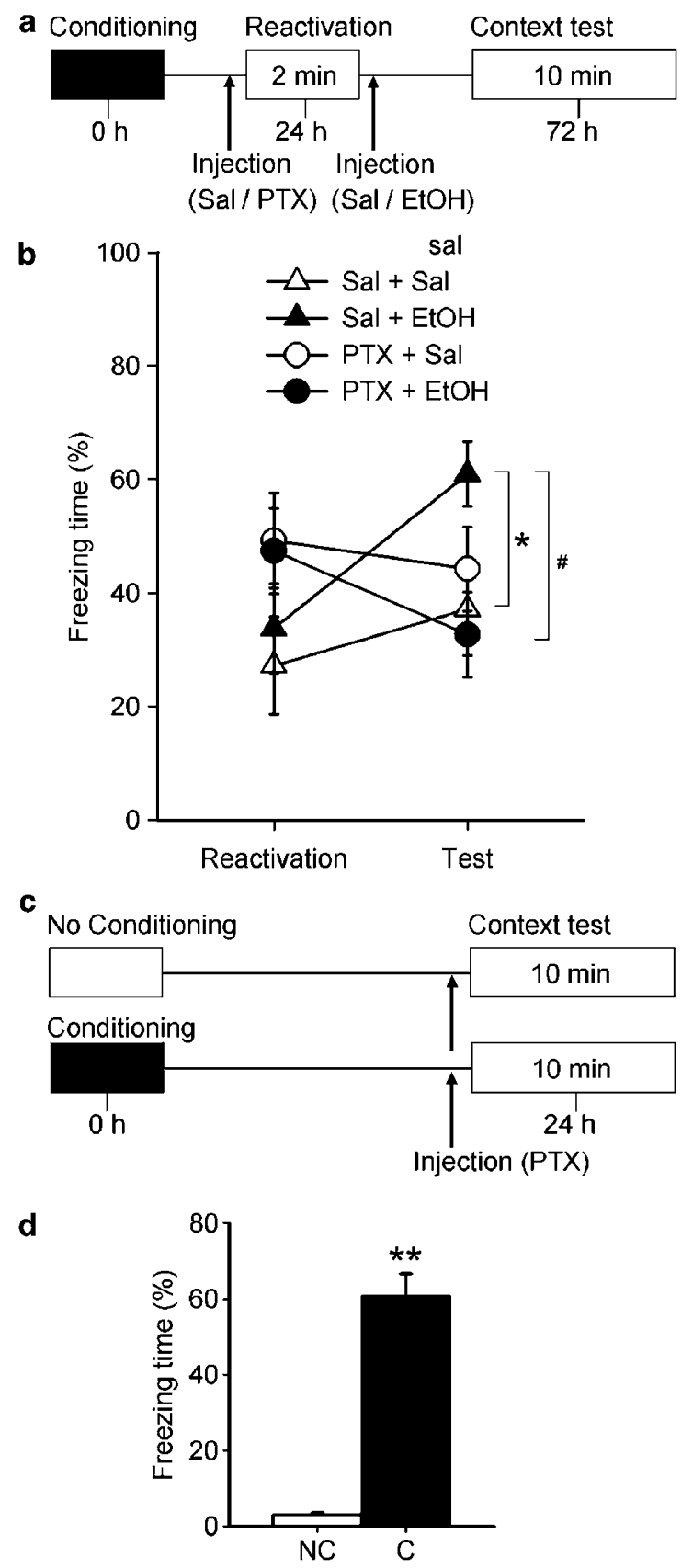

Figure 6 Picrotoxin inhibited memory enhancement induced by ethanol following reactivation. (a) The behavioral procedure used for experiment 8 (Sal + Sal, $n=12 ;$ Sal + EtOH, $n=12 ;$ PTX (Picrotoxin) + Sal, $n=12 ;$ PTX $+\mathrm{EtOH}, n=12$ ). Rats conditioned with weak footshock were administered saline or picrotoxin $20 \mathrm{~min}$ before re-exposure to the conditioning chamber for $2 \mathrm{~min}$, and injected with saline or ethanol immediately after reactivation. (b) Picrotoxin blocked memory enhancement induced by ethanol; *p $<0.05 \mathrm{Sal}+\mathrm{Sal}$ vs Sal $+\mathrm{EtOH} ;{ }^{\#} p<0.05 \mathrm{Sal}+\mathrm{EtOH}$ vs PTX + $\mathrm{EtOH}$. (c) The behavioral procedure used for experiment 9 (no conditioning (NC), $n=4$; conditioning $(C), n=4)$. (d) Freezing following picrotoxin administration was dependent on fear memory; ${ }^{*} *$ $p<0.0$ I vs no conditioning. Data represent the freezing time for the context test.

the chamber. Twenty-four hours later, both groups received picrotoxin and then $20 \mathrm{~min}$ later were re-exposed to the chamber for $10 \mathrm{~min}$ (Figure 6c). The conditioned group exhibited significantly longer freezing $(F(1,6)=32.57$; $p<0.01$ ) (Figure 6d). Therefore, freezing following picrotoxin 
during the reactivation session was dependent on conditioning and picrotoxin-treated rats were able to recall fear memory. The results suggest that the blocking effect of picrotoxin on ethanol is not due to a loss of retrieval.

\section{Effects of Post-Conditioning Injection with Ethanol}

To examine the effect of ethanol on the consolidation process of contextual fear memory, we administered ethanol immediately after conditioning and assessed memory $48 \mathrm{~h}$ later. We found that rats injected with ethanol after weak conditioning $(0.6 \mathrm{~mA}, 1 \mathrm{~s})$ showed significantly longer freezing $(\mathrm{F}(1,34)=4.59 ; p<0.05)$ (Figure $7 \mathrm{~b})$. However, there was no difference in the freezing response between the groups in strong conditioning $(1 \mathrm{~mA}, 2 \mathrm{~s})(\mathrm{F}(1,10)=0.05$; $p>0.05$ ) (Figure 7c). Since stronger conditioning (two footshocks $(2 \mathrm{~mA}, 2 \mathrm{~s})$ ) elicits longer freezing time than the 1-mA 2-s footshock followed by ethanol administration $(\mathrm{F}(1,10)=20.8 ; p<0.01)$, the insensitivity of ethanol in 1-mA 2-s footshock is not due to a ceiling effect.

\section{DISCUSSION}

We have demonstrated, for the first time, that ethanol enhances reactivated contextual fear memory. Rats receiving ethanol after reactivation, demonstrated longer freezing levels during the contextual test. Injection of ethanol without reactivation $24 \mathrm{~h}$ after conditioning had no effect and the administration of ethanol to non-conditioned rats after contextual exposure had no effect. This suggests that facilitation of freezing is not due to decreased locomotor activity or aversion induced by ethanol, and requires that memory is retrieved. This ethanol effect is not temporal but lasts for 2 weeks, suggesting that ethanol affects fear memory. Two-minute re-exposure did not induce memory extinction within reactivation session and among reactivation and test sessions. Rats receiving ethanol with reactivation exhibited longer freezing than those given ethanol

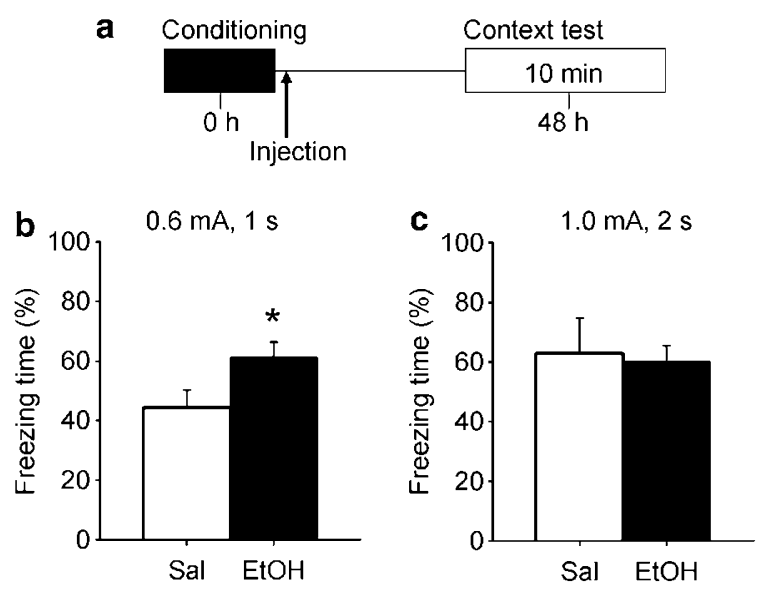

Figure 7 Memory enhancement by ethanol administration following weak conditioning. (a) The behavioral procedure used for experiment 10. Rats were conditioned with footshock (b, $0.6 \mathrm{~mA}$, I s; Sal, $n=18$; EtOH, $n=18 ; \mathrm{c}, \mathrm{ImA}, 2 \mathrm{~s}$; Sal, $n=6$; EtOH, $n=6$ ). (b, c) Rats conditioned with weak, but not strong, footshock were sensitive to ethanol; $* p<0.05$ vs saline. All data points represent freezing time for context test. without reactivation, suggesting that ethanol does not inhibit the memory decline (eg, extinction), but facilitates the fear memory. This ethanol effect depends on the strength of conditioned memory (see below). Taken together, we can say that ethanol affects the retrievalinduced process and enhances reactivated contextual fear memory.

What memory process does ethanol affect for memory enhancement? We explored the possibility that ethanol affects reconsolidation process. Memory retrieval triggers memory reconsolidation and extinction. The duration of reactivation helps to determine which of these processes is dominant (Suzuki et al, 2004). They showed that shorter reactivation induces reconsolidation and longer reactivation induces extinction. In this research, we confirmed that 30 -min retrieval incited persistent extinction. To examine the ethanol effect on longer reactivation, we administered ethanol after $30 \mathrm{~min}$ of reactivation. The freezing levels of the ethanol-treated group were not different from those of the saline-treated group during the contextual test. These results suggest that the effect of ethanol is specific for shortterm reactivation.

Then we investigated whether 2-min re-exposure triggered memory reconsolidation under our conditions. Many research studies reported that inhibition of protein synthesis before or immediately after memory retrieval disrupts the subsequent expression of memory, suggesting that reconsolidation depends on protein synthesis (Nader et al, 2000). However, contradictory results are reported in which memory stability does not require protein synthesis after retrieval in some cases (Lattal and Abel, 2001; Cammarota et al, 2004; Biedenkapp and Rudy, 2004). To clarify the effect of ethanol on the reconsolidation process, we checked whether our experimental conditions triggered reconsolidation. Instead of ethanol, we administered anisomycin, a de novo protein synthesis inhibitor, after $2 \mathrm{~min}$ of reactivation. The anisomycin-treated rats exhibited significantly shorter freezing during the contextual test. The decrease of freezing requires reactivation. These results suggest that 2-min reactivation changed consolidated memory into a labile state and then induced the reconsolidation process, which required de novo protein synthesis. Since the effect of ethanol is limited to shorter reactivation, which induces reconsolidation process, we consider that ethanol enhances fear memory through memory reconsolidation. The fact that reconsolidation can be potentiated is consistent with recent reports (Frenkel et al, 2005; Tronson et al, 2006).

There is a possibility that ethanol blocks memory extinction. However, we do not consider that extinction is involved in this ethanol effect because 2-min reactivation induces no or little extinction and because ethanol does not inhibit the memory decline but facilitates the fear memory. There is an alternative possibility that ethanol enhances spontaneous recovery from extinguished memory levels. However, we rule out it because 2-min re-exposure induces no or little extinction within reactivation session and among reactivation and test sessions.

What mechanisms are involved in the effect of the postretrieval administration of ethanol? Ethanol is known to have diverse pharmacological actions. Ethanol's amnesic effect is attributed mainly to the inhibition of NMDA receptors and potentiation of $\mathrm{GABA}_{\mathrm{A}}$ receptor-mediated 
inhibitory mechanisms (White et al, 2000). Several studies reported that NMDA receptor antagonists (MK-801, CPP) inhibited memory reconsolidation (Przybyslawski and Sara, 1997; Suzuki et al, 2004). It is unlikely that inhibiting NMDA receptors causes the enhancement of reconsolidation. By contrast, little is known about the involvement of $\mathrm{GABA}_{\mathrm{A}}$ receptors in reconsolidation. We investigated the involvement by using picrotoxin, a $\mathrm{GABA}_{\mathrm{A}}$ receptor antagonist. Figure 6 shows that picrotoxin blocks memory enhancement induced by post-retrieval administration of ethanol. It is possible that picrotoxin blocks memory retrieval itself. To clarify, we tested whether picrotoxin itself blocked memory retrieval or not. We found that freezing following picrotoxin was dependent on fear memory, suggesting that picrotoxin-treated rats can recall fear memory. These results suggest that the effect of ethanol is mediated by $\mathrm{GABA}_{\mathrm{A}}$ receptors. Ethanol causes diverse pharmacological actions through $\mathrm{GABA}_{\mathrm{A}}$ receptors. For example, it triggers a reward effect (Weiss and Porrino, 2002), an anxiolytic effect (Lister, 1987; Durcan and Lister, 1988) and the inhibition of the processing of other information. It is possible that these effects enhance reactivated memories. Moreover, there is an alternative possibility that transforming a memory from fixed to a labile state depends on $\mathrm{GABA}_{\mathrm{A}}$ receptors and ethanol's effect may need this transformation. Ben Mamou et al (2006) have dissociated memory retrieval from memory reactivation. Picrotoxin treatment may inhibit not retrieval but reactivation.

What brain regions are involved in the effect of the postretrieval administration of ethanol? Amygdala is an important component of the system involved in the control of fear memory (LeDoux, 2000). We hypothesize that amygdala is the region of action of ethanol. However, intra-amygdalar injection of ethanol does not affect reactivated fear memories. This result leads to two possibilities. First, ethanol affects other brain regions (eg, hippocampus). Hippocampus also plays an important role in acquision, consolidation, and reconsolidation of contextual fear memory (LeDoux, 2000; Debiec et al, 2002). There is a report that ethanol affects hippocampus preferentially in contextual fear conditioning (Melia et al, 1996). Note, however, that there are some differences between the work of Melia et al (1996) and our research. They reported the memory-disrupting effect of ethanol on new memories, but we report the memory-facilitating effect of ethanol on reactivated memories. Second, some metabolites of ethanol (eg, acetaldehyde) are involved in the memory enhancement. Acetaldehyde, the first metabolite in the metabolism of ethanol, is partly responsible for inhibitory effects induced by ethanol (Abe et al, 1999).

Recently, several studies focused on similar or distinct points between memory consolidation and reconsolidation (Alberini, 2005). In this report, we have proposed that ethanol enhances reconsolidation in contextual fear memory. However, the effect on consolidation in contextual fear memory has not been reported. To investigate this effect, we administered ethanol immediately after conditioning. The ethanol-treated rats demonstrated longer freezing during the contextual test. Since administrations $24 \mathrm{~h}$ after conditioning have no effect, ethanol does not affect the maintenance process. As indicated above, injection of ethanol itself does not induce fearful response. Taken together, this suggests that ethanol enhances the consolidation process in contextual fear memory. We have shown that the ethanol effect on reactivated memory is similar to the effect on new memories. These results are consistent with the notion that consolidation and reconsolidation have, at least in part, common molecules and mechanisms (Alberini, 2005).

Many research studies reported the effect of post-training treatment with ethanol. In 1979, Alkana and Parker (1979) showed that the immediate post-training injection of ethanol enhances retention in a one-trial passive avoidance task in mice. Since then, several studies reported the effect on humans. They revealed that post-training administration of ethanol improved verbal recall (Parker et al, 1980; Lamberty et al, 1990; Tyson and Schirmuly, 1994), visual recognition (Parker et al, 1981), verbal recognition (Bruce and Pihl, 1997), and kinesthetic memory (Hewitt et al, 1996). In animals, post-training ethanol treatment improves performance in a water-finding task in rats (Melia et al, 1986) and social memory in rats (Prediger and Takahashi, 2003). However, some reports showed conflicting results. Aversano et al (2002) demonstrated that post-training administration of ethanol impaired memory consolidation in a one-trial inhibitory avoidance task. Prado de Carvalho et al (1978) showed that a near-lethal dose of ethanol did not affect memory consolidation of shuttle avoidance task and inhibitory avoidance task.

We have demonstrated that post-conditioning administration of ethanol facilitates contextual fear memory and that this effect depends on the strength of conditioned memory. Post-training administration of some amnesic drugs (AP-5 or benzodiazepines) was shown to improve memory, depending on memory strength (LaLumiere et al, 2004; Voigt et al, 1996). To examine whether the effect of ethanol depends on memory strength, we used two levels of footshock. Ethanol enhanced fear memory when administered immediately after mild footshock applied during conditioning. In contrast, ethanol was ineffective after strong footshock. These results suggest that memory strength has a decisive influence on the effect of posttraining ethanol administration.

Memory facilitation induced by ethanol administered during post-reactivation depends on memory strength as well as the post-conditioning effects. When rats were conditioned with mild footshock, ethanol enhanced their reactivated fear memories. The reactivated memories elicited by strong footshock are insensitive to ethanol. Ethanol may not affect strong reactivated memory; similarly post-conditioning ethanol administration does not influence strong conditioned memory. However, recent findings suggested that stronger memory is more resistant to amnesic agents after retrieval, and that longer re-exposure time is required to transform stronger memory from a stable state to a labile state (Suzuki et al, 2004). In the stronger conditioning experiment, $2 \mathrm{~min}$ of reactivation may not elicit the memory reconsolidation, despite the effect of ethanol.

It is known that especially after we experience stress, our alcohol intake increases (Pohorecky, 1981). In animal studies, unpredictable exposure to stressful stimuli induces ethanol consumptive behavior in rats (Nash and Maickel, 
1985) and conditioned fear stress induces ethanol-associated place preference (Matsuzawa et al, 1998). Considering that alcohol has reward (Weiss and Porrino, 2002) and anxiolytic effects (Lister, 1987; Durcan and Lister, 1988), we can say that alcohol ingestion is a way to escape from aversive memories. In this paper, we examined the influence of ethanol on reactivated fear memory. We demonstrated that post-reactivation ethanol administration did not diminish but actually intensified the original memory. Taking account of the relationship between stress and ethanol ingestion, fear memory facilitation induced by ethanol may cause a stronger preference for ethanol.

\section{ACKNOWLEDGEMENTS}

We thank Dr Kazuhito Nakao for comments on the experiments. We are also grateful to Sayaka Fukuda and Takuma Kitanishi for discussions.

\section{DISCLOSURE/CONFLICT OF INTEREST}

The authors declare that this work was supported by a Grant-in-Aid for Science Research from the Ministry of Education, Culture, Sports, Science, and Technology of Japan (no.19390019, to NM) and Takeda Science Foundation (to NM).

\section{REFERENCES}

Abe K, Yamaguchi S, Sugiura M, Saito H (1999). The ethanol metabolite acetaldehyde inhibits the induction of long-term potentiation in the rat dentate gyrus in vivo. Br J Pharmacol 127: 1805-1810.

Abel T, Lattal KM (2001). Molecular mechanisms of memory acquisition, consolidation and retrieval. Curr Opin Neurobiol 11: 180-187.

Alberini CM (2005). Mechanisms of memory stabilization: are consolidation and reconsolidation similar or distinct processes? Trends Neurosci 28: 51-56.

Alkana RL, Parker ES (1979). Memory facilitation by post-training injection of ethanol. Psychopharmacology (Berl) 66: 117-119.

Aversano M, Ciamei A, Cestari V, Passino E, Middei S, Castellano C (2002). Effects of MK-801 and ethanol combinations on memory consolidation in CD1 mice: involvement of GABAergic mechanisms. Neurobiol Learn Mem 77: 327-337.

Ben Mamou C, Gamache K, Nader K (2006). NMDA receptors are critical for unleashing consolidated auditory fear memories. Nat Neurosci 9: 1237-1239.

Biedenkapp JC, Rudy JW (2004). Context memories and reactivation: constraints on the reconsolidation hypothesis. Behav Neurosci 118: 956-964.

Bruce KR, Pihl RO (1997). Forget 'drinking to forget': enhanced consolidation of emotionally charged memory by alcohol. Exp Clin Psychopharmacol 5: 242-250.

Cammarota M, Bevilaqua LR, Medina JH, Izquierdo I (2004). Retrieval does not induce reconsolidation of inhibitory avoidance memory. Learn Mem 11: 572-578.

Crews FT, Morrow AL, Criswell H, Breese G (1996). Effects of ethanol on ion channels. Int Rev Neurobiol 39: 283-367.

Debiec J, LeDoux JE, Nader K (2002). Cellular and systems reconsolidation in the hippocampus. Neuron 36: 527-538.

Durcan MJ, Lister RG (1988). Time course of ethanol's effects on locomotor activity, exploration and anxiety in mice. Psychopharmacology (Berl) 96: 67-72.
Frenkel L, Maldonado H, Delorenzi A (2005). Memory strengthening by a real-life episode during reconsolidation: an outcome of water deprivation via brain angiotensin II. Eur J Neurosci 22: $1757-1766$.

Grant KA, Lovinger DM (1995). Cellular and behavioral neurobiology of alcohol: receptor-mediated neuronal processes. Clin Neurosci 3: 155-164.

Hanchar HJ, Dodson PD, Olsen RW, Otis TS, Wallner M (2005). Alcohol-induced motor impairment caused by increased extrasynaptic GABA(A) receptor activity. Nat Neurosci 8: 339-345.

Hewitt GP, Holder M, Laird J (1996). Retrograde enhancement of human kinesthetic memory by alcohol: consolidation or protection against interference? Neurobiol Learn Mem 65: 269-277.

LaLumiere RT, Pizano E, McGaugh JL (2004). Intra-basolateral amygdala infusions of AP-5 impair or enhance retention of inhibitory avoidance depending on training conditions. Neurobiol Learn Mem 81: 60-66.

Lamberty GJ, Beckwith BE, Petros TV, Ross AR (1990). Posttrial treatment with ethanol enhances recall of prose narratives. Physiol Behav 48: 653-658.

Lattal KM, Abel T (2001). Different requirements for protein synthesis in acquisition and extinction of spatial preferences and context-evoked fear. J Neurosci 21: 5773-5780.

LeDoux JE (2000). Emotion circuits in the brain. Annu Rev Neurosci 23: 155-184.

Lister RG (1987). The use of a plus-maze to measure anxiety in the mouse. Psychopharmacology (Berl) 92: 180-185.

Lister RG, Eckardt MJ, Weingartner H (1987). Ethanol intoxication and memory. Recent developments and new directions. Recent Dev Alcohol 5: 111-126.

Matsuzawa S, Suzuki T, Misawa M (1998). Conditioned fear stress induces ethanol-associated place preference in rats. Eur $J$ Pharmacol 341: 127-130.

Melia KF, Ehlers CL, LeBrun CJ, Koob GF (1986). Post-learning ethanol effects on a water-finding task in rats. Pharmacol Biochem Behav 24: 1813-1815.

Melia KR, Ryabinin AE, Corodimas KP, Wilson MC, Ledoux JE (1996). Hippocampal-dependent learning and experience-dependent activation of the hippocampus are preferentially disrupted by ethanol. Neuroscience 74: 313-322.

Miyakawa T, Yamada M, Duttaroy A, Wess J (2001). Hyperactivity and intact hippocampus-dependent learning in mice lacking the M1 muscarinic acetylcholine receptor. J Neurosci 21: 5239-5250.

Nader K (2003). Memory traces unbound. Trends Neurosci 26: $65-72$.

Nader K, Schafe GE, Le Doux JE (2000). Fear memories require protein synthesis in the amygdala for reconsolidation after retrieval. Nature 406: 722-726.

Nash Jr JF, Maickel RP (1985). Stress-induced consumption of ethanol by rats. Life Sci 37: 757-765.

Nie Z, Schweitzer P, Roberts AJ, Madamba SG, Moore SD, Siggins GR (2004). Ethanol augments GABAergic transmission in the central amygdala via CRF1 receptors. Science 303: 1512-1514.

Parker ES, Birnbaum IM, Weingartner H, Hartley JT, Stillman RC, Wyatt RJ (1980). Retrograde enhancement of human memory with alcohol. Psychopharmacology (Berl) 69: 219-222.

Parker ES, Morihisa JM, Wyatt RJ, Schwartz BL, Weingartner H, Stillman RC (1981). The alcohol facilitation effect on memory: a dose-response study. Psychopharmacology (Berl) 74: 88-92.

Pohorecky LA (1981). The interaction of alcohol and stress. A review. Neurosci Biobehav Rev 5: 209-229.

Prado de Carvalho L, Vendite DA, Izquierdo I (1978). A near-lethal dose of ethanol, given intraperitoneally, does not affect memory consolidation of two different avoidance tasks. Psychopharmacology (Berl) 59: 71-74. 
Prediger RD, Takahashi RN (2003). Ethanol improves short-term social memory in rats. Involvement of opioid and muscarinic receptors. Eur J Pharmacol 462: 115-123.

Przybyslawski J, Sara SJ (1997). Reconsolidation of memory after its reactivation. Behav Brain Res 84: 241-246.

Rescorla RA, Heth CD (1975). Reinstatement of fear to an extinguished conditioned stimulus. J Exp Psychol Anim Behav Process 1: 88-96.

Suzuki A, Josselyn SA, Frankland PW, Masushige S, Silva AJ, Kida S (2004). Memory reconsolidation and extinction have distinct temporal and biochemical signatures. J Neurosci 24: 4787-4795.

Tronson NC, Wiseman SL, Olausson P, Taylor JR (2006). Bidirectional behavioral plasticity of memory reconsolidation depends on amygdalar protein kinase A. Nat Neurosci 9: 167-169.

Tyson PD, Schirmuly M (1994). Memory enhancement after drinking ethanol: consolidation, interference, or response bias? Physiol Behav 56: 933-937.

Voigt JP, Morgenstern E, Fink H (1996). Memory-enhancing effects of benzodiazepines in mice. Eur Neuropsychopharmacol 6: 253-255.

Weiss F, Porrino LJ (2002). Behavioral neurobiology of alcohol addiction: recent advances and challenges. J Neurosci 22: 3332-3337.

White AM, Matthews DB, Best PJ (2000). Ethanol, memory, and hippocampal function: a review of recent findings. Hippocampus 10: $88-93$. 